
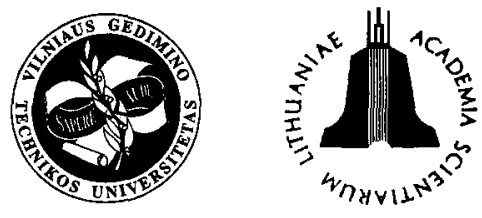

ISSN $1392-3730$

JOURNAL OF CIVIL ENGINEERING AND MANAGEMENT

http:/www.vtu.lt/english/editions

2003, Vol IX, No 4, 260-265

\title{
INFLUENCE OF CHISEL SHARE FOR THE DESTRUCTION OF CONCRETE
}

\author{
Friedel Peldschus ${ }^{1}$, Jens-Thorsten Wild ${ }^{2}$ \\ ${ }^{\prime}$ Leipzig University of Applied Science, 132 Karl Liebknecht St., D-04277 Leipzig, Germany. \\ E-mail:peldschu@fbb.htwk-leipzig.de \\ ${ }^{2}$ fera - Bau Leipzig, Lampestr. 9, D-04107 Leipzig, Germany.E-mail: wild@fera-bau.de
}

Received 22 May 2003; accepted 11 Aug 2003

\begin{abstract}
The energy shares occurring in the chiselling process were investigated in order to increase the productivity of the manual destruction of concrete. Apart from the influences of notch energy and cleaving energy, the energy loss due to friction forces was considered. As a result two new chisel forms were developed as a combination of sharp cutting edge and steep wedge. The effectiveness of these chisels was tested under experimental conditions as well as under reality conditions. It was found that the application of lateral tips at the chisel leads to an improved processing performance.
\end{abstract}

Keywords: concrete, chiselling process, crack propagation, impact loading, colour indicators, friction force device.

\section{Introduction}

The manual destruction of concrete has gained more importance during the second half of the $90 \mathrm{~s}$, because the need for redevelopment has risen, in particular, in urban office and residential buildings. Additionally the redevelopment of reinforced-concrete buildings also requires the application of hand-guided machines.

Today's state of research of the concrete destruction using hand-guided drill and chisel hammers is wellproven concerning the unit tool-machine. An enormous increase in the quality of these tools was achieved during the last years and decades due to the steady optimisation of the mechanics, electronics, control, pneumatics etc, eg by the electro-pneumatic principle (Doepper) [1].

While the optimisation of the machine (drill and chisel hammer) including the machine-tool interface has reached a state that it can hardly be improved yet, the optimisation of the interface tool-concrete is still in an initial stage. It is for this reason that this study attempts to improve the tool-concrete interface, which has so far not been considered or only to a small extent [2].

Basic tests were performed with the standard chisel forms flat and pointed chisel with the aim of improving the manual destruction of concrete. Considering the findings about the crack and fracture characteristics of the concrete under impact loading during the chiselling process, possibilities of the optimisation of the chisel cutting edge were investigated. A fundamental precondition for the basic tests was to look at every single impact in detail, ie the accurate quantitative recording of the transmitted energy and the investigations about the energy shares. This was achieved building a self-developed droptest device and a friction-force test device [3].

\section{Depiction of the typical crack propagation}

The process of a concrete piece breaking off during chiselling begins with the creation of two separate initial cracks placed laterally of the cutting edge. After that the crack surfaces extend laterally into the depth, depicted by the change of the grey shade according to Fig 1 . The typical crack pattern shows the transition from darker to lighter shades. In the experiments the crack pattern was traced using colour indicators [4].

Initially the cracks followed the longitudinal direction of the cutting edge, and then in diagonal direction towards the plate edge or cube edge respectively.

The surface extension of the two lateral initial cracks increased in oblique direction laterally downwards. The applied colour indicators could penetrate the concrete below the cutting edge. Even when deeper crack surfaces had already developed beside the cutting edge, the material below the cutting edge did not separate. Only when a half of the ultimate crack surface had developed in vertical direction, the two cracks merged. After that the crack propagated further downwards and upwards. A vast majority of the experiments showed that the complete cracking up to the lower edge occurred even before the cracking below the cutting edge.

In this way it was found that crack occurs last in the surface below the cutting edge [4]. Fig 2 and 3 show examples of the colour tracking of the crack propagation during the chiselling process. 


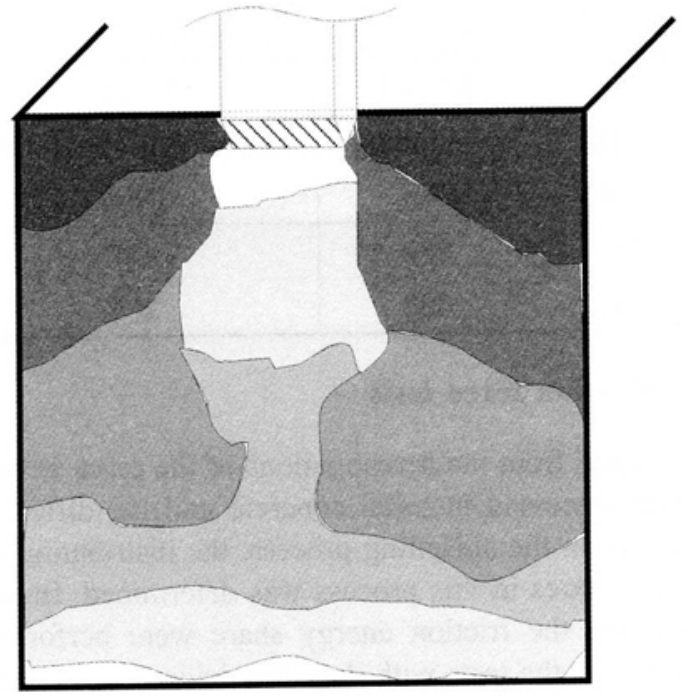

Fig 1. Colour indicators placed behind the course of a crack

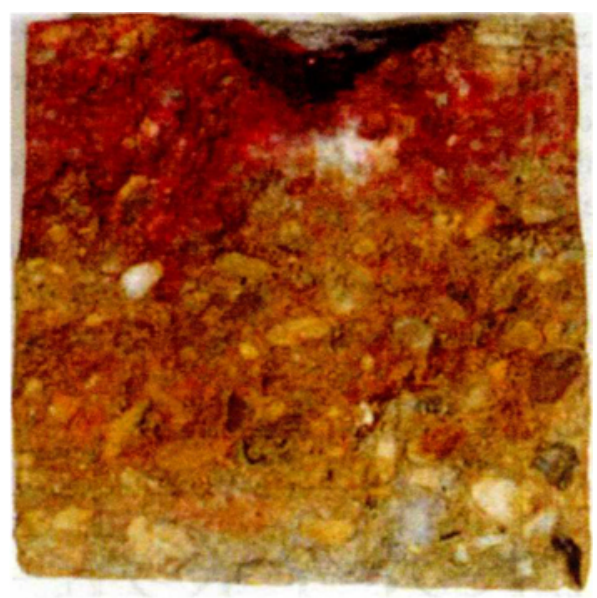

Fig 2. Colour tone in the test cube

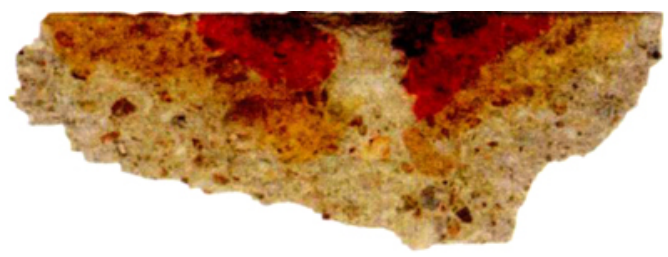

Fig 3. Colour tone in the fragment

\section{Energy shares}

The description of the energy distribution over the separate stages was another important basis for a detailed study of the chiselling process. The impact energy transmitted by the drop piston was here divided into energy shares that are mainly separate. A distinct measurement of these energy shares is not feasible in dynamic processes, and the concrete makes it even more difficult. For this reason the dominant energy form was chosen for describing each of the stages.
The energy shares were mainly divided into two main stages of the cracking process - the stage up to the crack initialisation and the crack-propagation stage up to the following fracture. The first stage was further divided.

As far as the energy losses are concerned, only the friction energy shares were investigated experimentally. Other energy dissipative processes as the loss due to sound waves or the loss by the elastic properties (rebound) were not considered in the experiments. This was due to the fact that the priority for the investigations of the chisel cutting edge was to obtain knowledge about the improvement of the processing. The motivation to investigate the friction losses was to find out whether the friction has such a share in the whole process that it should be thought about reducing it. A friction reduction could be achieved by a lubricant.

\subsection{Notching and cleaving energy}

The notch energy share should be understood as the energy which is used to:

- let the cutting edge intrude sufficiently into the concrete surface in order to transmit the necessary forces for cleaving. By displacing the crushed material of hardened cement paste and aggregates (concrete powder) the necessary strengthening of the contact area below the lateral cutting surface is induced.

- To damage the concrete up to its strength. This damage is weakening the structure, during which the micro-structure cracks in the concrete are enlarged to fine cracks.

Besides the necessary energy input for a fracture, a point resistance occurs during the whole chiselling process. This is considered as part of the notch energy share.

After this crack start, caused by the notching energy, mainly the cleaving energy occurs, apart from the point resistance, the cleaving energy share that transmits the impact energy of the chisel to the contact surfaces and thus lets the crack propagate further.

\subsubsection{Notching stage (including point resistance)}

For the experiments to investigate the energy shares the notching energy share was further divided by the experiment performance. A separation of the energy shares was allowed by a special nature of the test specimens.

For the first series of specimens the displacing share was eliminated. This share includes the crushing of the concrete and its displacement to the surface or into the concrete structure (compacting in order to create a solid contact surface).

For this purpose concrete blocks with different depths were formed (Fig 4). The comparison of the energy shares, however, only refers to a pre-formed intrusion depth of $15 \mathrm{~mm}$, because the fracture occurred near this depth in normal specimens. 


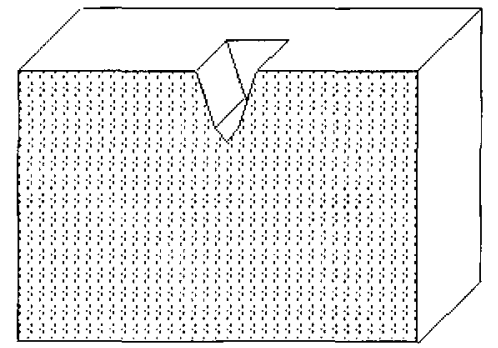

Fig 4. Notching energy test

A comparison of preformed specimens shows clearly that with an increasing deformation and thus a larger contact area the total energy decreases.

It was found that with an increasing preforming depth the energy input decreases. Nevertheless, an effort, which cannot be neglected, remains also at increasing contact areas. The energy of a single impact is not sufficient for an immediate crack initialisation. Despite the prepared contact surface, an energy input is necessary for crushing the concrete and creating a solid contact surface for the chisel. The point resistance still occurs.

This shows that the impact energy of $8,76 \mathrm{Nm}$ transmitted to the specimen during the tests is not sufficient to split the concrete without preloading. A damage of the structure of the concrete components is needed for crack propagation.

A crack tracking was also performed during the experiments for the energy shares. But the differences between the tests with and without preforming were very small.

\subsubsection{Cleaving stage (without point resistance)}

A six-to-eight millimetre deep space was created in the area of the very tip of the chisel by gently grinding the concrete below the cutting edge where the flattening takes place. In this way the point resistance was eliminated (Fig 5). The energy input could then be used entirely for the cleaving effect of the chisel. This remaining amount of energy was associated with the cleaving and friction resistance. The tests were performed for two prepared intrusion depths.

Table and Fig 5 show a comparison of the energy input in tests with preformed and with additionally grinded (elimination of the point resistance) blocks.

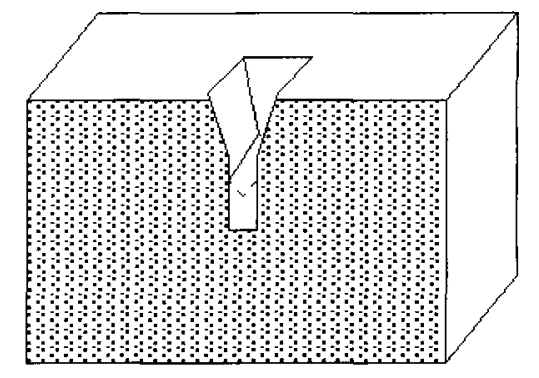

Fig 5. Cleaving energy test
Tests with pre-formed and pre-drilled specimen

\begin{tabular}{|c|c|c|}
\hline $\begin{array}{c}\text { Depth } \\
{[\mathrm{mm}]}\end{array}$ & $\begin{array}{c}\text { Energy } \\
\text { preforming } \\
{[\mathrm{Nm}]}\end{array}$ & $\begin{array}{c}\text { Energy } \\
\text { preforming + predrilled } \\
{[\mathrm{Nm}]}\end{array}$ \\
\hline 15 & 880 & 437 \\
20 & 653 & 265 \\
\hline
\end{tabular}

\subsection{Friction force tests}

Apart from the investigations of the crack behaviour of the processed material concrete and the different influences on the chiselling process, the distribution of the energy shares in this process was determined. Investigations into the friction energy share were performed in addition to the tests with the drop device [3] for separating separate energy shares like notching energy or cleaving energy. It should be mentioned that the experiments to determine the friction force were not performed under a dynamic load, because such tests would have meant an enormous technical effort and because they were not the main work focus.

The experiments to determine the friction force were performed under quasi-static loading.

With three force gauges the resultant lateral forces were measured. With these measured forces the friction forces and the friction coefficient could be determined for the wedge of a chisel cutting edge on a concrete surface loaded by chiselling [5].

\section{Schnitt A-A}

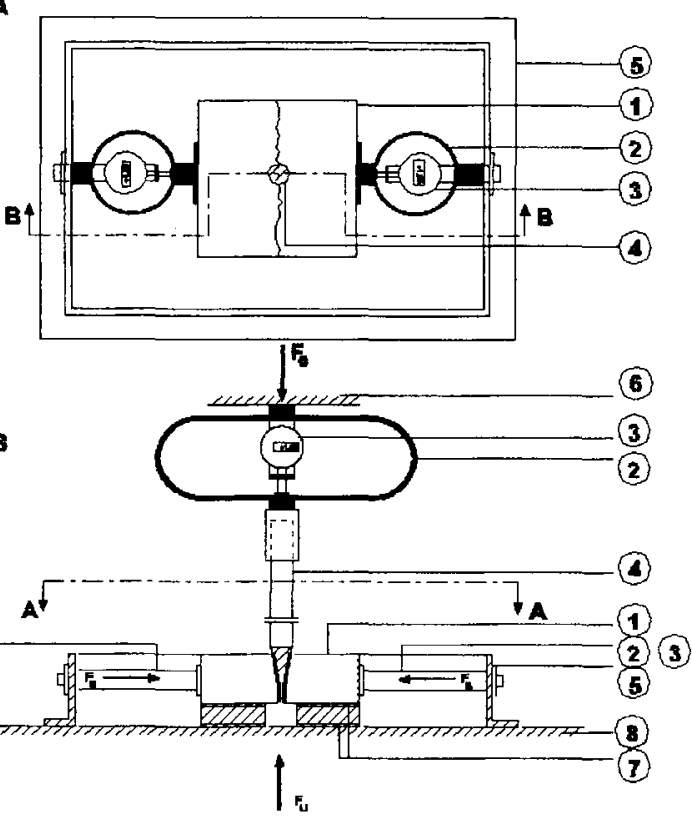

Fig 5. Principal drawing of the friction force test device

The meaning of the symbols:

$\mathrm{F}$ - transmitted force

$\mathrm{F}_{\mathrm{H}}$ - half force

$\mathrm{F}_{\mathrm{S}}$ - lateral force

$F_{R}$ - friction force

$\mathrm{F}_{\mathrm{N}}$ - normal force

$F_{G}$ - resultant force 


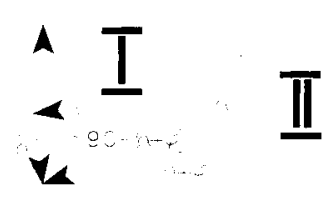

Fig 6. Force relations at the wedge

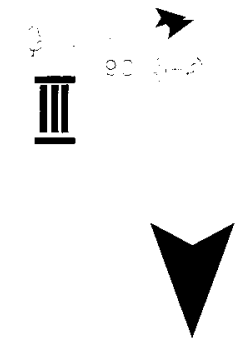

The friction force is calculated according to (1)

$$
F_{R}=\frac{F_{H}}{\sqrt{\sin \alpha}\left|\frac{F_{S}+F_{H} * \operatorname{tang} \alpha}{F_{H}-F_{S} * \operatorname{tang} \alpha}\right|+\cos \alpha}
$$

Here the friction coefficient has the value:

$$
\operatorname{tang} \varphi=\begin{aligned}
& F_{H}-F_{S} \operatorname{tang} \alpha \\
& F_{S}+F_{H} \operatorname{tang} \alpha
\end{aligned}
$$

The friction coefficient at the chisel wedge is on average $m=0,4$. This means that during the sliding of the chisel cutting edge over the concrete the cleaving forces, caused by the wedge effect, are reduced by more than a third by overcoming the friction forces.

These experiments were performed in order to fulfil the prerequisites and conditions for creating a model as detailed as possible to be used to divide the acting forces in the chiselling process into its energy shares by using numerical simulation.

The different energy shares are depicted in Fig 7.

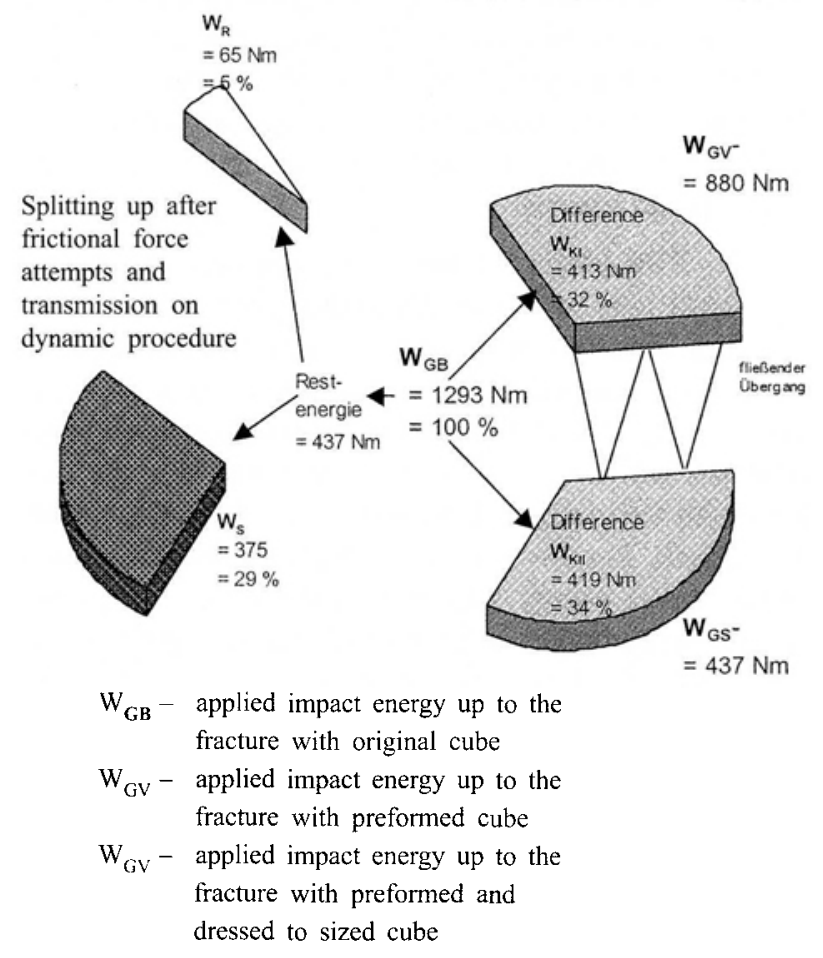

Fig 7. Distribution of the energy shares in the chiselling process

\section{Investigations with two new chisel forms}

The performed experiments and their evaluation showed the advantages and disadvantages of the tested chisel modifications. Considering the possibilities to apply these findings to further improving the cutting-edge form, two new chisel forms (chisel A and B) were made. These should give a further increase in performance.

Additionally, differences occurred in the performance order of the chisels between the different experiment settings (drop device and reality tests). The reasons for these differences in performance - expressed by a change of the order - were supposed mainly in the different amounts of single-impact energy.

For designing the modified chisel forms mainly the experiments with the chisel hammer were analysed. The good chisel properties of the chisels 1 and 4 were crucial. The main reason for their good performance in the test series with the real-life chisel hammer is the unchanged width of the cutting edge. The large lateral surfaces can support the cleaving effects better.

A greater depth is reached in the real-life chisel tests before the fracture occurs. The experiments with the chisel hammer have proved that, despite the equal edge distance of $3,5 \mathrm{~cm}$, significantly greater total intrusion depths occurred than in the tests with the drop device. This hints the need for a greater contact area in order to transmit the energy that is necessary for the crack propagation. It becomes evident looking at the relatively poor performance of chisels 5 and 6 . The area is reduced further by the abrupt transition from the contact surface, which narrows trapezoidally, and the lateral burr. The brittle material concrete cannot adapt to such a sharp change of the form, so that no cleaving force can be transmitted there.

A better performance in the chiselling process can only be achieved if the ratio of intrusion ability and cleaving ability is well balanced.

In the tests with the first six chisel modifications, a positive effect could be noticed by changes at the lateral edges.

While in the series at the drop device and the reallife chiselling tests with $3,5 \mathrm{~cm}$ edge distance mainly a positive effect of the lateral wedge was observed, a shift towards the chisels with a sharp lateral burr occurred in the real-life tests with $4,5 \mathrm{~cm}$ edge distance. It was then concluded that with an increased intrusion depth und thus a larger contact area an improved intrusion ability has a positive effect despite the reduction by the sharp burr.

\section{Concluding statements about the chisel modifica- tions. Interpretation of the results}

The analysis of the results was split into three main parts.

1. The evaluation of the two new chisels

The experiments with the two new chisel modifications $\mathrm{A}$ and $\mathrm{B}$ proved that the best performance is 


\section{Chisel A}

Chisel B
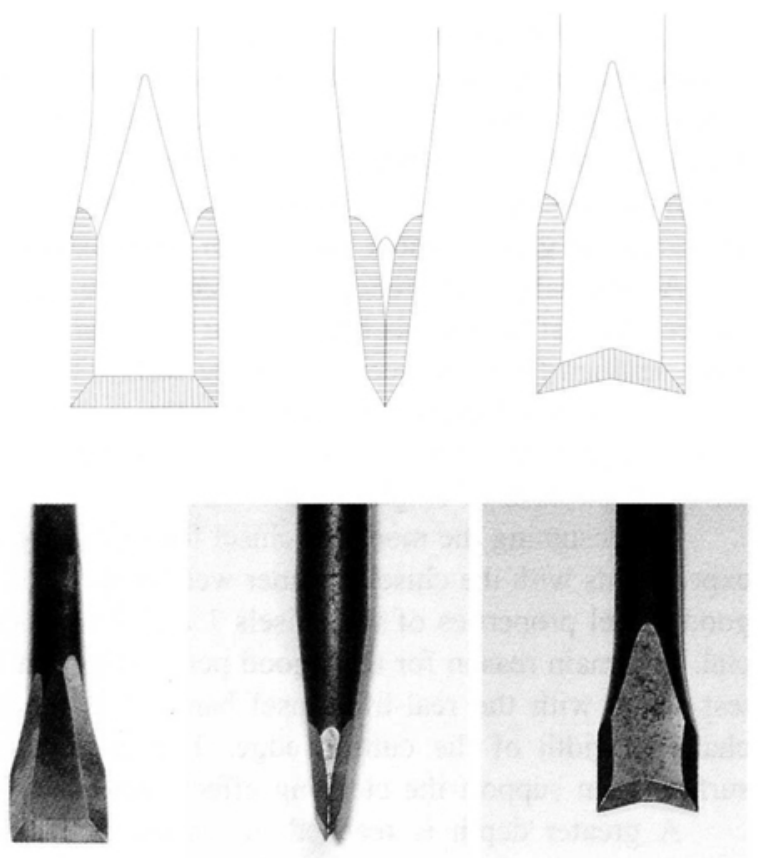

Fig 8. Distribution of the energy shares in the chiselling process

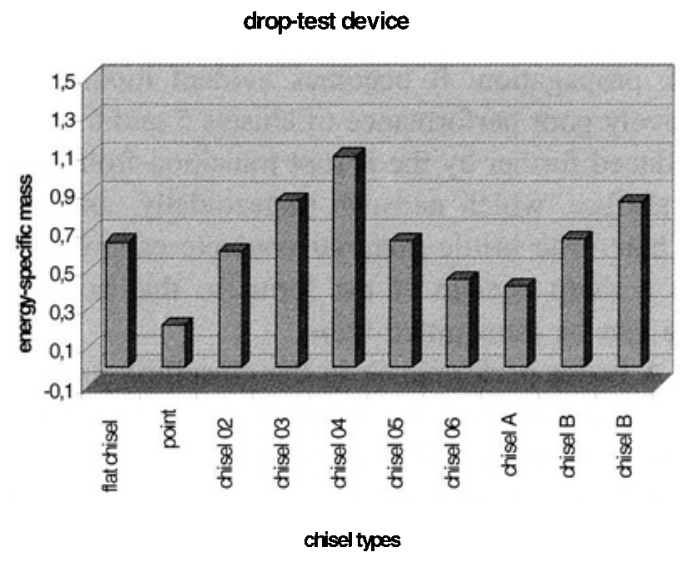

Fig 9. Results of the laboratory experiments

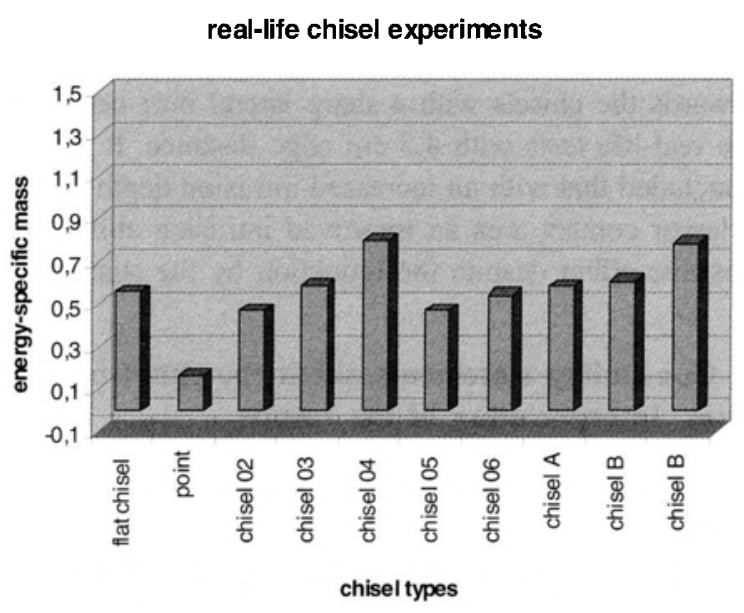

Fig 10. Results of the real-life chisel experiments achieved with chisels that have two lateral tips. This was reliably determined by the profound tests with the medium impact mass and it was confirmed in the tests using the large impact mass. Thus it can be clearly concluded that the application of two lateral tips allows for an increase of $50 \%$ in the processing.

Furthermore the tests with the chisel modifications 1 to 6 have shown that a conical forming of the chisel cutting edge does not cause the expected improvement by reducing the chisel contact surface area. That is why the chisel width was not changed for the chisels $A$ and $B$, but the intrusion resistance was only changed by sharpening the edges of the chisels. The results of the experiments with the chisels $\mathrm{A}$ and $\mathrm{B}$ confirmed this assumption.

\section{The comparison of the drop tests with the real- life chiselling tests}

A crucial question raised by these investigations of the six chisel modifications was if the tests at the drop device could be compared with real-life tests using the chisel hammer. In the test series of three different impact energies, differences occurred in the transmitted amount of energy for an equal break-off mass and the same chisel modification. While the tests with the great impact energy supported the results of the profound tests with medium impact energy, the tests with the small impact energy did not show the same results as the main experiments. The chisel modifications are depicted in Fig 11 (comparison of the energy input to fracture).

It can be seen from this comparison that large differences in the energy input to fracture between the two test devices - drop device and real-life hammer - are due to the different amounts of single-impact energy. It was, however, observed that the energy input to fracture is always a little higher for the chisel hammer than for the drop device. Therefore it can be supposed that a slightly more energy is lost by the high impact frequency of the chisel hammer.

3. The effect of the single-impact energy on variations of the cutting-edge geometry

The questions of the single-impact energy effect on variations of the cutting-edge geometry could be answered more clearly. The differences in the order of chisel modifications, which had been observed comparing the drop tests with the real-life tests, were also observed with the new chisels. For this reason, the experiments with a small single-impact energy were performed at the drop device and the experiments with a great single-impact energy were performed using the chisel hammer. All the experiments prove the statement that the chisel forms with lateral tips have a better processing performance at higher single-impact energies. Thus the better processing is not only due to the conditions at the drop device. Looking at the effect of the lateral tips it must be assumed that the transmission of the impact energy is changed. While for the normal form of the cutting edge the stress concentration is located directly below it, the purpose of the chisels with lateral tips was to move this stress concen- 


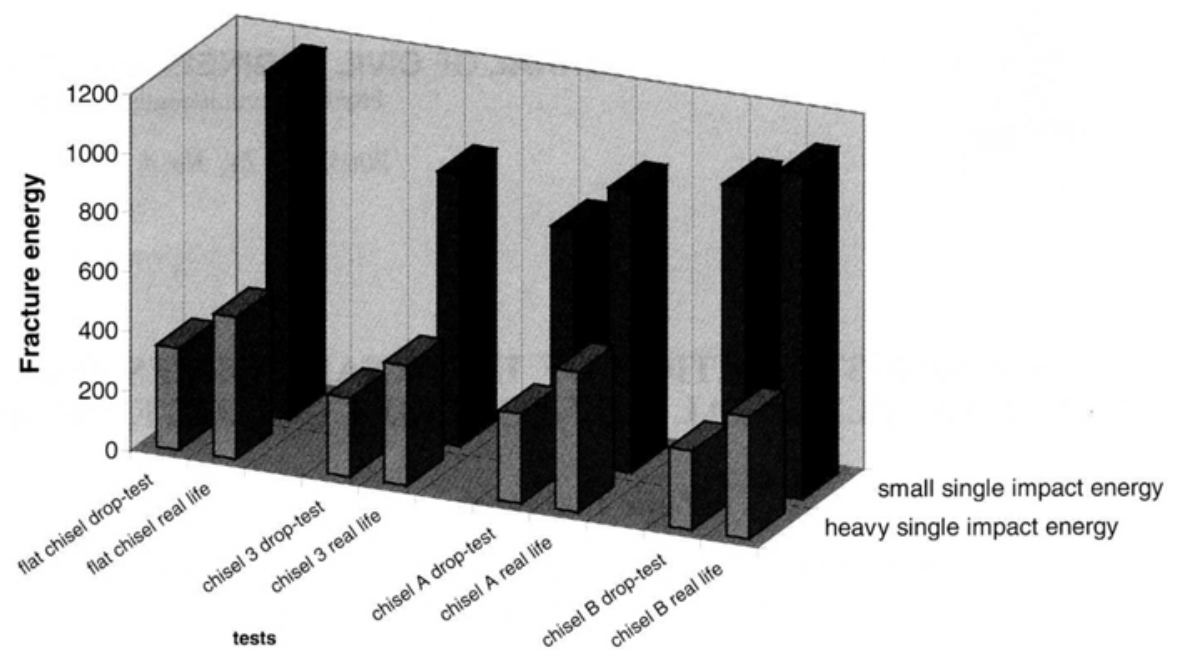

Fig 11. Comparison of the energy input to fracture at different single-impact energies

tration to the place of the crack initialisation. An increase in strength is then observed below the impact areas. The application of the lateral impact force, which was meant to develop the crack more efficiently once initialised, first leads to a prevention of the crack initialisation due to the increase in strength of the concrete below the lateral tips [6]. This increased strength can only be overcome efficiently by an increase in the single-impact energy at the same time. Hence, the advantage of changing the impact energy flow is partly compensated by increasing the strength there, where the crack initialisation normally occurs. Therefore the use of chisels with lateral tips is to be considered disadvantageous for combination hammers with a low single-impact energy.

\section{Summary and future perspectives}

It turned out that the performed mechanical investigations required a lot of effort. Therefore the question was raised if the investigation of this type of problem can be made more efficient by applying numerical simulation, for instance, the finite element analysis.

For the structural analysis using the finite element method (FEM) a discretised geometric model of the real structures is needed as well as mathematical descriptions of the external loads and the relevant properties of the materials. Up to now the application of this method in civil engineering is basically restricted to static conditions. Two characteristics have to be considered for the application of the FEM to investigate the mechanical processing of concrete.

First, due to a high velocity of the loading a dynamical simulation is required, and the modelling of the mechanical processing must include crack initialisation and particles breaking-off. Therefore material failure is to be described too. As the problems are somewhat similar, the experiences and advances in the field of crash simulation should be considered.

Second, concrete is, in a fully-cured state, a heterogeneous structure consisting of a matrix and other components with pores of varying size. FEM material mod- els are of phenomenological origin in the sense of the continuum mechanics. They are restricted to the description of a phenomenon without considering the microstructure. In order to characterise the material, mathematical equations are used, which do not vary within a finite element. Such an element is the smallest homogeneous unit of the model. Hence, for modelling concrete this homogeneity can only be kept with a coarse approximation or with extremely high costs of modelling.

Besides the determination of general material values for the simulation, the performed experimental investigations are to be seen as a basis for the application of the FEM. After a successful validation the FEM could be used in order to reduce the experimental costs of the tool development $[6,7]$.

\section{References}

1. DIN VDE 0740 Manual electric machines (items) (Handgeführte Elektrowerkzeuge (Begriffe)). Köln: Beuth, 1985. 01.26 p. (in German).

2. Zhao, G. Development und optimisation of a hydraulic rotary hammer (Entwicklung und Optimierung eines hydraulischen Bohrhammers). Düsseldorf: VDI-Verl., 1997. 108 p. (in German).

3. Peldschus F., Wild J.-Th. Experimental investigations of chiselling of solid concrete. Journal of Civil Engineering and Management, 2003, Vol IX, No 1, p. 3-10.

4. Römpp H. The chemical and molecular biology encyclopaedia (Lexikon Chemie und Molekulärbiologie). Stuttgart: Thieme. 2000. 725 p. (in German).

5. Klemt $\mathrm{K}$. The bearing and deformation behaviour of concrete subjected to uniaxial compressive short-term loading. Düsseldorf : VDI-Verl., 2002. 118 p.

6. Curbach M. Strength enhancement of concrete on high loading velocity (Festigkeitssteigerung von Beton bei hohen Belastungsgeschwindigkeiten). Karlsruhe: Institut for Massive structure and building material technology, Univ. Karlsruhe, 1987. 154 p. (in German).

7. Ferber F. Numeric and experimental investigations of crackafflicted structures. Paderborn: Habil.-scripture, 2001. 260 p. (in German). 